\title{
Receptor for Advanced Glycation Endproducts (RAGE), Its Ligands, and Soluble RAGE: Potential Biomarkers for Diagnosis and Therapeutic Targets for Human Renal Diseases
}

\author{
Eun Ji Lee, Jong Hoon Park* \\ Department of Biological Science, Sookmyung Women's University, Seoul 140-742, Korea
}

\begin{abstract}
Receptor for advanced glycation endproducts (RAGE) is a multi-ligand receptor that is able to bind several different ligands, including advanced glycation endproducts, high-mobility group protein (B)1 (HMGB1), S-100 calcium-binding protein, amyloid- $\beta$-protein, Mac-1, and phosphatidylserine. Its interaction is engaged in critical cellular processes, such as inflammation, proliferation, apoptosis, autophagy, and migration, and dysregulation of RAGE and its ligands leads to the development of numerous human diseases. In this review, we summarize the signaling pathways regulated by RAGE and its ligands identified up to date and demonstrate the effects of hyper-activation of RAGE signals on human diseases, focused mainly on renal disorders. Finally, we propose that RAGE and its ligands are the potential targets for the diagnosis, monitoring, and treatment of numerous renal diseases.
\end{abstract}

Keywords: advanced glycosylation end-product receptor, kidney diseases, signal transduction

\section{Introduction}

Receptor for advanced glycation endproducts (RAGE) is a transmembrane protein that belongs to the immunoglobulin superfamily [1]. As its name implicates, it can bind to advanced glycation endproducts, the resulting product of non-enzymatic glycosylation [2], and it also has the ability to interact with multiple ligands having common motifs as a so-called multi-ligand receptor. The ligands include highmobility group protein (B) 1 (HMGB1), S-100 calcium- binding protein, amyloid- $\beta$-protein, Mac- 1 , and phosphatidylserine [3]. Interaction between RAGE and its ligands activates various cellular processes, including inflammation, proliferation, apoptosis, autophagy, and migration [4]. Expression of RAGE is different, depending on the organ, developmental stage, and cellular condition [5]. It is highly expressed during the embryonic stage, whereas it is mostly kept at low levels in adults [5, 6]. Mostly, it is stimulated by cellular stresses, such as inflammation, and is therefore easily found to be abnormally over-expressed in many hu- man chronic diseases [7]. Accumulation of advanced glycation endproducts (AGEs) is highly associated with the pathogenesis of diabetes, which causes serious consequences on metabolic systems [8]. In addition, expression of S100 proteins is reported to be involved in many cancers, including breast, lung, kidney, and thyroid cancers. Mostly, their up-regulation promotes tumorigenesis by stimulating metastasis through the activation of relevant transcription factors or by acting as chemoattractants $[9,10]$. In addition to cancers, RAGE and its ligands are abnormally regulated in various types of chronic immune diseases, such as atherosclerosis, Alzheimer disease, and arthritis [7]. Increasing evidence demonstrates the critical role of RAGE signaling in many other human diseases and suggests its stimulating factors as potential biomarkers for diagnosis or therapy. In this review, we are going to summarize the RAGE signaling pathway and its contribution to the pathogenesis of human diseases, focused specifically on kidney diseases. Further, we propose the possibility of using RAGE and its ligands as therapeutic targets. 


\section{RAGE and Its Splice Variants}

Human RAGE is encoded by a gene located on major histocompatibility complex (MHC) class III region on chromosome 6 [11]. The mature RAGE has three main parts, consisting of extracellular, transmembrane, and cytosolic regions. The extracellular region is composed of one V-type and two C-type domains, and the V-type domain is responsible for interaction with multiple RAGE ligands. The transmembrane domain anchors RAGE to the cellular membrane, and signals transduce into the cell via the cytosolic domain $[1,12]$. Besides, RAGE variants, represented by three forms, called N-truncated, dominantnegative, and soluble RAGE, can be generated either by natural alternative splicing or by the action of membraneassociated proteases (Fig. 1) [1]. The N-truncated form of RAGE lacks a V-domain so that it can not interact with ligands, whereas the cytosolic domain is missing in dominant-negative RAGE, which results in no signal transduction, though it can bind to ligands. Without the transmembrane domain, soluble RAGE is formed and is able to circulate out of the cell and act as decoys by preventing ligands from binding to RAGE [13]. Therefore, soluble RAGE can neutralize the effect of RAGE ligands, and many studies have suggested that this function might be applied to inhibition of RAGE signals in human diseases [14].

\section{RAGE Signaling Pathways}

RAGE and its ligands are highly expressed in developmental stages and enhance survival of neurons during development [15]. After embryonic development, these genes are down-regulated and kept a low expression levels during normal life, except for certain conditions, such as injury and aging [15]. Interestingly, unlike other receptors, expression of RAGE is positively regulated by its ligand stimulation, which means that increasing concentration of ligands leads to up-regulation of RAGE. So, RAGE signals are accelerated more and more by the accumulation of signal stimulants [16].

RAGE is found on the cell surface of various immune cells, and most of its ligands are mainly secreted by immune cells, including macrophages and dendritic cells; therefore one of the major roles of RAGE is involved in inflammation $[7,14]$. Stimulation of RAGE by its ligands activates the proinflammatory transcription factor nuclear factor kappa B (NF-кB), and it then translocates into the nucleus and activates its target genes, including several kinds of cytokines responsible for innate or adaptive immunity $[17,18]$. Also, NF-кB can bind to glyoxalase (Glo1) and suppress its inhibitory activity on AGE production [19]. Target genes of NF- $\mathrm{B}$ include anti-apoptotic genes, such as Bcl proteins; therefore, cell survival is also under the control of NF-kB [16]. In addition, the mitogen-activated protein kinase signaling pathway itself can be activated by RAGE stimulation. Specifically, activated RAGE is able to stimulate ERK, p38, and JNK, and it leads to induction of cell proliferation [20]. Another process involved in RAGE signaling is cell migration via transforming growth factor beta (TGF- $\beta$ ) signal cascades. TGF- $\beta$ is activated by RAGE ligand stimulation and enhances its downstream signals. They include the Ras homolog family and Rho-associated kinase, and activation of these genes leads to stable actin filament formation and cell migration [21]. Due to RAGE signals being concerned with

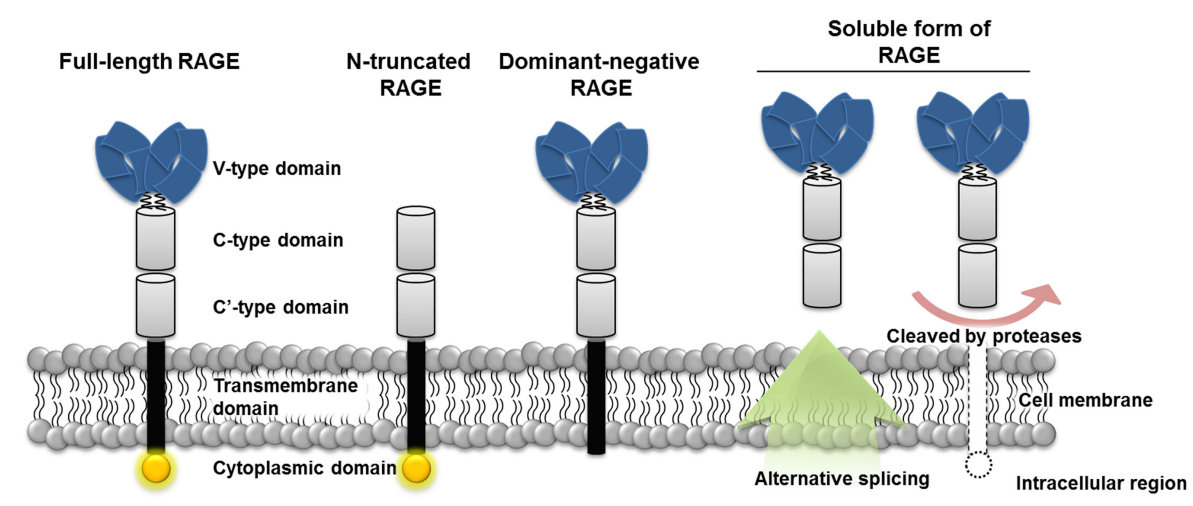

Fig. 1. Structures of receptor for advanced glycation end products and its three main isoforms. Full-length receptor for advanced glycation endproducts (RAGE) has three different extracellular domains $\left(\mathrm{V}, \mathrm{C}, \mathrm{C}^{\prime}\right)$ and one cytosolic domain. Multi-ligands bind to the $\mathrm{V}$-type domain and transduce signals through the intracellular domain. The $\mathrm{N}$-truncated isoform lacks the V-type domain, which fails to have receptor-ligand interactions. The dominant-negative form has no cytosolic domain and is not able to transduce signals into the cell. Soluble RAGE is formed either by alternative splicing or protease activity and is secreted and prevents ligands from binding to RAGE. V, variable domain; C, constant domain. 
multiple cellular signaling pathways, in particular with immune responses and cell survival, the development of numerous human diseases is associated with it. They include diabetes, inflammatory diseases, cancers, and cardiovascular diseases, and blockade of RAGE is increasingly proposed as a therapeutic target [4].

\section{RAGE Ligands and Kidneys}

Expression of RAGE and its ligands is kept at a low level in a wide range of cell types, including endothelium, smooth muscle cells, mononuclear phagocytes, neurons, and cardiac myocytes [22]. However, when RAGE ligands are accumulated by pathological development of relevant diseases, it alters the structure of tissues as well as compromise protein function in them [23, 24]. Also, increased circulating RAGE ligands induce the expression of their receptor, RAGE; therefore, RAGE ligand signals are stimulated as the ligands increase [16]. In kidneys, accumulation of RAGE ligands is well studied to contribute to both diabetic and non-diabetic nephropathy (DN). Firstly, AGEs have been found primarily to be up-regulated in renal basement membranes in diabetic nephropathies and in some other renal diseases, including glomerulosclerosis and arteriosclerosis, which are not related to diabetes [25]. In diabetes, AGEs are highly accumulated by increasing mitochondrial production of reactive oxygen species, followed by high intracellular glucose levels [26]. Abnormally high concentrations of AGEs impair proximal tubular cells, which are responsible for regulation of AGE metabolism, resulting in damage to those cells and their function $[27,28]$. Also, kidneys play key roles in the clearance of AGEs, such that the impaired structure of the kidneys by AGEs fails to degrade them [29]. In turn, more and more AGEs are accumulated as the kidney is damaged by the action of AGEs, and finally, it results in DN [27, 28, 30]. Recently, increasing evidence has shown that RAGE ligands other than AGEs, including HMGB1 and S-100 proteins, are also up-regulated in renal diseases. HMGB1 is a nuclear protein essential for regulating the physical interaction of DNA with certain transcription factors, such as p53 [29]; however, when it is released extracellularly, it is able to mediate inflammatory reactions and contribute to the pathogenesis of several diseases, including glomerulonephritis, lupus nephritis, and renal cell carcinoma (RCC) [31, 32]. In addition, cell proliferation, migration, and invasion as well as inflammation are also activated in RCC via ERK1/2 activation [32].

Interaction between RAGE and its ligands changes renal cellular processes, including inflammation, proliferation, and migration, and they are highly significant processes to keep the normal function of kidneys; therefore, dysregu- lation of RAGE or its ligand concentrations might give fatal effects, leading to the development and pathogenesis of renal diseases.

\section{RAGE and Renal Diseases}

\section{Diabetic nephropathy}

$\mathrm{DN}$ is one of the diseases triggered by diabetes and finally leads to renal failure and elevation of arterial blood pressure [33]. Cellular mechanisms involved in the development and pathogenesis of DN include glomerular hypertrophy, production of oxidative stresses, fibrosis, and inflammation, followed by hyperglycemia. As mediators, renin, angiotensin, aldosterone, protein kinases, and NADPH are existing, and hyper-activation of them results in up-regulation of fibrotic and inflammatory factors, including TGF- $\beta$ [33-36]. Also, hyperglycemia stimulates glycation and oxidation of macromolecules, which result in the formation of AGEs as endproducts [37]. Accumulated AGEs join in the up-regulation of inflammatory factors and oxidative stress and accelerate the pathogenesis of the disease [38].

\section{Cardio-renal syndrome}

Cardio-renal syndrome is a combined disorder having both heart and kidney dysfunction. The primary failed organ can be either the heart or kidney, and in both cases, the one that is diseased earlier impairs the other one, and finally, they negatively affect each other [37]. One of the suggested mechanisms making these two organs negatively interact with each other is mediated by AGEs [39]. Accumulation of AGEs is commonly observed in patients with both heart failure and renal disorders [40, 41]. With heart failure, increase of AGEs leads to inflammation, fibrosis, and delayed calcium uptake, which subsequently result in diastolic dysfunction. In addition, accumulation of AGEs in renal dysfunction is negatively affected by highly activated inflammation and fibrosis, and further damage of kidney structure impairs its own function of AGE clearance [39]. Symptoms of the disease might be enhanced by this vicious cycle, as well as with other multifactorial signaling pathways involved in the pathogenesis.

\section{Autosomal dominant polycystic kidney disease}

Autosomal dominant polycystic kidney disease is one of the most highly prevalent inherited disorders and is characterized by the development of thousands of epitheliallined, fluid-filled cysts in the kidney [42]. Cell proliferation, inflammation, and fibrosis are the major processes of the development and pathogenesis of the disease, and various factors, including chemokines and growth factors, are engaged in these signaling pathways [43-45]. Recently, several 
studies have reported that expression of HMGB1 and certain types of S-100 (S-100A8, 9) is increased around the cystic region and proposed them to be disease-stimulating agents [46-48]. So, inflammatory and growth factors secreted by cyst-lined epithelial cells and increased circulating AGEs finally result in compromised renal function at the end stage of the disease.

\section{Renal cell carcinomas}

RAGE and its ligands are reported to be abnormally expressed in various cancers, including breast, lung, kidney, thyroid, prostate, and oral cancers. S100 protein, one of the representative ligands of RAGE, which has at least over 20 subtypes, has been well reviewed to play major roles in tumor-related processes, including proliferation, apoptosis, metastasis, and invasion [10]. In renal cancer, S100A1 has been observed to be highly expressed in papillary RCC and oncocytoma, which are relatively common types of renal cancers, whereas it is absent in chromophobe RCC [49]. Likewise, a broad range of S100 proteins has been detected differently, depending on the subtype of renal carcinoma, which means that it should be a useful biomarker for discriminating the subtype of renal cancers if it is correctly examined [50]. In addition, HMGB1, another ligand of RAGE, has appeared to be up-regulated and interacts with its receptor for promoting cell proliferation, migration, and invasion via the ERK pathway in RCC [32]. From this evidence, RAGE and its multiple ligands are increasingly suggested as biomarkers and therapeutic targets for different types of renal carcinomas.

\section{Conclusions and Perspectives}

In various types of renal diseases, including both diabeticand non-diabetic disorders, RAGE and its ligands are commonly observed to be dysregulated. The major problem of these phenomena in renal diseases might be the vicious cycle that impairs kidney by increased AGEs or when other RAGE ligands fail to remove them, causing these ligands to accumulate and the relevant signals to accelerate. Therefore, numerous studies suggest RAGE and its ligands as new potential targets for the diagnosis, monitoring, and treatment of renal diseases that have abnormal regulation of them. Firstly, ligands expression or secretion level can be used as a diagnostic or staging marker. S100B is already used in evaluations after treatment of melanoma in a clinical setting [51]. Secondly, more trials targeting RAGE ligands either with inhibitors of them or the soluble form of RAGE have been reported. Soluble RAGE treatment significantly alleviates the symptoms of nephritis in vivo [52], and in cancer studies, nude mice injected with soluble RAGE- over-expressing cells have shown remarkable inhibition of tumor formation [53]. With inhibitors of AGEs, several agents, including aminoguanidine and pyridoxamine, have been tried in humans; some of them have shown enhanced renal function in diabetic patients, but these trials were terminated early because of safety concerns $[54,55]$. Finally, more recently, epigenetic regulation by microRNAs of molecules involved in RAGE signaling pathways is also being studied [56].

\section{References}

1. Neeper M, Schmidt AM, Brett J, Yan SD, Wang F, Pan YC, et al. Cloning and expression of a cell surface receptor for advanced glycosylation end products of proteins. J Biol Chem 1992;267: 14998-15004.

2. Reddy S, Bichler J, Wells-Knecht KJ, Thorpe SR, Baynes JW. N epsilon-(carboxymethyl)lysine is a dominant advanced glycation end product (AGE) antigen in tissue proteins. Biochemistry 1995;34:10872-10878.

3. Ramasamy R, Yan SF, Schmidt AM. The diverse ligand repertoire of the receptor for advanced glycation endproducts and pathways to the complications of diabetes. Vascul Pharmacol 2012;57:160-167.

4. Xie J, Méndez JD, Méndez-Valenzuela V, Aguilar-Hernández MM. Cellular signalling of the receptor for advanced glycation end products (RAGE). Cell Signal 2013;25:2185-2197.

5. Brett J, Schmidt AM, Yan SD, Zou YS, Weidman E, Pinsky D, et al. Survey of the distribution of a newly characterized receptor for advanced glycation end products in tissues. Am J Pathol 1993;143:1699-1712.

6. Ramasamy R, Yan SF, Schmidt AM. RAGE: therapeutic target and biomarker of the inflammatory response: the evidence mounts. J Leukoc Biol 2009;86:505-512.

7. Chuah YK, Basir R, Talib H, Tie TH, Nordin N. Receptor for advanced glycation end products and its involvement in inflammatory diseases. Int J Inflam 2013;2013:403460.

8. Calcutt NA, Cooper ME, Kern TS, Schmidt AM. Therapies for hyperglycaemia-induced diabetic complications: from animal models to clinical trials. Nat Rev Drug Discov 2009;8:417-429.

9. Donato R, Cannon BR, Sorci G, Riuzzi F, Hsu K, Weber DJ, et al. Functions of S100 proteins. Curr Mol Med 2013;13:24-57.

10. Salama I, Malone PS, Mihaimeed F, Jones JL. A review of the S100 proteins in cancer. Eur J Surg Oncol 2008;34:357-364.

11. Sugaya K, Fukagawa T, Matsumoto K, Mita K, Takahashi E, Ando A, et al. Three genes in the human MHC class III region near the junction with the class II: gene for receptor of advanced glycosylation end products, PBX2 homeobox gene and a notch homolog, human counterpart of mouse mammary tumor gene int-3. Genomics 1994;23:408-419.

12. González I, Romero J, Rodríguez BL, Pérez-Castro R, Rojas A. The immunobiology of the receptor of advanced glycation end-products: trends and challenges. Immunobiology 2013;218: 790-797.

13. Hudson BI, Carter AM, Harja E, Kalea AZ, Arriero M, Yang H, et al. Identification, classification, and expression of RAGE 
gene splice variants. FASEB J 2008;22:1572-1580.

14. Maillard-Lefebvre H, Boulanger E, Daroux M, Gaxatte C, Hudson BI, Lambert M. Soluble receptor for advanced glycation end products: a new biomarker in diagnosis and prognosis of chronic inflammatory diseases. Rheumatology (Oxford) 2009;48:1190-1196.

15. Huttunen HJ, Kuja-Panula J, Sorci G, Agneletti AL, Donato R, Rauvala $\mathrm{H}$. Coregulation of neurite outgrowth and cell survival by amphoterin and S100 proteins through receptor for advanced glycation end products (RAGE) activation. J Biol Chem 2000;275:40096-40105.

16. Bierhaus A, Humpert PM, Morcos M, Wendt T, Chavakis T, Arnold B, et al. Understanding RAGE, the receptor for advanced glycation end products. J Mol Med (Berl) 2005;83: 876-886.

17. Schmidt AM, Yan SD, Yan SF, Stern DM. The biology of the receptor for advanced glycation end products and its ligands. Biochim Biophys Acta 2000;1498:99-111.

18. Barnes PJ, Karin M. Nuclear factor-kappaB: a pivotal transcription factor in chronic inflammatory diseases. NEngl J Med 1997;336:1066-1071.

19. Yao D, Brownlee M. Hyperglycemia-induced reactive oxygen species increase expression of the receptor for advanced glycation end products (RAGE) and RAGE ligands. Diabetes 2010;59:249-255.

20. Sparvero LJ, Asafu-Adjei D, Kang R, Tang D, Amin N, Im J, et al. RAGE (Receptor for Advanced Glycation Endproducts), RAGE ligands, and their role in cancer and inflammation. $J$ Transl Med 2009;7:17.

21. Higashi T, Sano H, Saishoji T, Ikeda K, Jinnouchi Y, Kanzaki T, et al. The receptor for advanced glycation end products mediates the chemotaxis of rabbit smooth muscle cells. Diabetes 1997;46:463-472.

22. Schmidt AM, Yan SD, Wautier JL, Stern D. Activation of receptor for advanced glycation end products: a mechanism for chronic vascular dysfunction in diabetic vasculopathy and atherosclerosis. Circ Res 1999;84:489-497.

23. Monnier VM, Sell DR, Nagaraj RH, Miyata S, Grandhee S, Odetti P, et al. Maillard reaction-mediated molecular damage to extracellular matrix and other tissue proteins in diabetes, aging, and uremia. Diabetes 1992;41 Suppl 2:36-41.

24. Tanji N, Markowitz GS, Fu C, Kislinger T, Taguchi A, Pischetsrieder M, et al. Expression of advanced glycation end products and their cellular receptor RAGE in diabetic nephropathy and nondiabetic renal disease. J Am Soc Nephrol 2000;11:1656-1666.

25. Bohlender JM, Franke S, Stein G, Wolf G. Advanced glycation end products and the kidney. Am J Physiol Renal Physiol 2005; 289:F645-F659.

26. Vlassara H. The AGE-receptor in the pathogenesis of diabetic complications. Diabetes Metab Res Rev 2001;17:436-443.

27. Simm A, Munch G, Seif F, Schenk O, Heidland A, Richter H, et al. Advanced glycation endproducts stimulate the MAP-kinase pathway in tubulus cell line LLC-PK1. FEBS Lett 1997;410: 481-484.

28. Saito A, Takeda T, Sato K, Hama H, Tanuma A, Kaseda R, et al. Significance of proximal tubular metabolism of advanced gly- cation end products in kidney diseases. Ann N Y Acad Sci 2005; 1043:637-643.

29. Ulloa L, Batliwalla FM, Andersson U, Gregersen PK, Tracey $\mathrm{KJ}$. High mobility group box chromosomal protein 1 as a nuclear protein, cytokine, and potential therapeutic target in arthritis. Arthritis Rheum 2003;48:876-881.

30. Gugliucci A, Bendayan M. Renal fate of circulating advanced glycated end products (AGE): evidence for reabsorption and catabolism of AGE-peptides by renal proximal tubular cells. Diabetologia 1996;39:149-160.

31. Zhu P, Xie L, Ding HS, Gong Q, Yang J, Yang L. High mobility group box 1 and kidney diseases (Review). Int J Mol Med 2013;31:763-768

32. Lin L, Zhong K, Sun Z, Wu G, Ding G. Receptor for advanced glycation end products (RAGE) partially mediates HMGB1ERKs activation in clear cell renal cell carcinoma. J Cancer Res Clin Oncol 2012;138:11-22.

33. Arora MK, Singh UK. Molecular mechanisms in the pathogenesis of diabetic nephropathy: an update. Vascul Pharmacol 2013;58:259-271.

34. Singh R, Alavi N, Singh AK, Leehey DJ. Role of angiotensin II in glucose-induced inhibition of mesangial matrix degradation. Diabetes 1999;48:2066-2073.

35. Ohshiro Y, Ma RC, Yasuda Y, Hiraoka-Yamamoto J, Clermont $\mathrm{AC}$, Isshiki $\mathrm{K}$, et al. Reduction of diabetes-induced oxidative stress, fibrotic cytokine expression, and renal dysfunction in protein kinase Cbeta-null mice. Diabetes 2006;55:3112-3120.

36. Asaba K, Tojo A, Onozato ML, Goto A, Quinn MT, Fujita T, et al. Effects of NADPH oxidase inhibitor in diabetic nephropathy. Kidney Int 2005;67:1890-1898.

37. Ronco C, Haapio M, House AA, Anavekar N, Bellomo R. Cardiorenal syndrome. J Am Coll Cardiol 2008;52:1527-1539.

38. Vlassara H, Uribarri J, Cai W, Goodman S, Pyzik R, Post J, et al. Effects of sevelamer on HbAlc, inflammation, and advanced glycation end products in diabetic kidney disease. Clin J Am Soc Nephrol 2012;7:934-942.

39. Willemsen S, Hartog JW, Heiner-Fokkema MR, van Veldhuisen DJ, Voors AA. Advanced glycation end-products, a pathophysiological pathway in the cardiorenal syndrome. Heart Fail Rev 2012;17:221-228.

40. Willemsen S, Hartog JW, Hummel YM, van Ruijven MH, van der Horst IC, van Veldhuisen DJ, et al. Tissue advanced glycation end products are associated with diastolic function and aerobic exercise capacity in diabetic heart failure patients. Eur J Heart Fail 2011;13:76-82.

41. Yamada K, Miyahara Y, Hamaguchi K, Nakayama M, Nakano $\mathrm{H}$, Nozaki O, et al. Immunohistochemical study of human advanced glycosylation end-products (AGE) in chronic renal failure. Clin Nephrol 1994;42:354-361.

42. Harris PC, Torres VE. Polycystic kidney disease. Annu Rev Med 2009;60:321-337.

43. Ye M, Grant M, Sharma M, Elzinga L, Swan S, Torres VE, et al. Cyst fluid from human autosomal dominant polycystic kidneys promotes cyst formation and expansion by renal epithelial cells in vitro. J Am Soc Nephrol 1992;3:984-994.

44. Norman J. Fibrosis and progression of autosomal dominant polycystic kidney disease (ADPKD). Biochim Biophys Acta 
2011;1812:1327-1336.

45. Vernon MA, Mylonas KJ, Hughes J. Macrophages and renal fibrosis. Semin Nephrol 2010;30:302-317.

46. Nakamura T, Sato E, Fujiwara N, Kawagoe Y, Yamada S, Ueda $\mathrm{Y}$, et al. Changes in urinary albumin excretion, inflammatory and oxidative stress markers in ADPKD patients with hypertension. Am J Med Sci 2012;343:46-51.

47. Nakamura T, Kawagoe Y, Ueda Y, Yamada S, Koide H. Hemoperfusion treatment in a septic shock patient with autosomal dominant polycystic kidney disease and increased HMGB1 protein levels. Blood Purif 2011;32:139-142.

48. Park EY, Seo MJ, Park JH. Effects of specific genes activating RAGE on polycystic kidney disease. Am J Nephrol 2010;32: 169-178.

49. Li G, Gentil-Perret A, Lambert C, Genin C, Tostain J. S100A1 and KIT gene expressions in common subtypes of renal tumours. Eur J Surg Oncol 2005;31:299-303.

50. Lin F, Yang W, Betten M, Teh BT, Yang XJ; French Kidney Cancer Study Group. Expression of S-100 protein in renal cell neoplasms. Hum Pathol 2006;37:462-470.

51. Hamberg AP, Korse CM, Bonfrer JM, de Gast GC. Serum $\mathrm{S} 100 \mathrm{~B}$ is suitable for prediction and monitoring of response to chemoimmunotherapy in metastatic malignant melanoma. Melanoma Res 2003;13:45-49.

52. Lee SW, Park KH, Park S, Kim JH, Hong SY, Lee SK, et al. Soluble receptor for advanced glycation end products alleviates nephritis in (NZB/NZW)F1 mice. Arthritis Rheum 2013;65:1902-1912.

53. Hallam KM, Li Q, Ananthakrishnan R, Kalea A, Zou YS, Vedantham $S$, et al. Aldose reductase and AGE-RAGE pathways: central roles in the pathogenesis of vascular dysfunction in aging rats. Aging Cell 2010;9:776-784.

54. Bolton WK, Cattran DC, Williams ME, Adler SG, Appel GB, Cartwright $\mathrm{K}$, et al. Randomized trial of an inhibitor of formation of advanced glycation end products in diabetic nephropathy. Am J Nephrol 2004;24:32-40.

55. Williams ME, Bolton WK, Khalifah RG, Degenhardt TP, Schotzinger RJ, McGill JB. Effects of pyridoxamine in combined phase 2 studies of patients with type 1 and type 2 diabetes and overt nephropathy. Am J Nephrol 2007;27:605-614.

56. Lan HY. Transforming growth factor-beta/Smad signalling in diabetic nephropathy. Clin Exp Pharmacol Physiol 2012;39: 731-738. 